\title{
Origen y alcance de la doctrina estadounidense del Derecho constitucional $^{1-2}$
}

\author{
James Bradley Thayer ${ }^{3}$ \\ Trad. de Mariano Vitetta
}

I. ¿Cómo surgió en nuestro país la doctrina que permite al Poder Judicial declarar la inconstitucionalidad de las leyes y tratarlas como si fueran nulas? ¿Cuál es su verdadero alcance?

Llama la atención que las constituciones de los estados no hayan otorgado esta facultad de manera expresa, sino implícita. En la primera constitución que se sancionó, nada se dijo que pudiera dar lugar claramente a esta doctrina. Recién después de la aprobación de la Constitución federal se mencionó algo al respecto, como en el artículo XII de la Constitución de Kentucky de 1792. Al principio, en algunos distritos se negaba o se ponía en duda la existencia de esa facultad. Recién en 1825, en un fuerte voto en disidencia, el juez Gibson, de Pensilvania, uno de los magistrados más destacados de los Estados Unidos que posteriormente presidió la Suprema Corte de ese estado, negó rotundamente dicha facultad en tanto no estuviera expresamente incluida en una constitución. Por lo tanto, la negó de manera genérica según las disposiciones de las constituciones

\footnotetext{
1 Traducción del inglés al español realizada por Mariano Vitetta, traductor público de inglés y abogado de la Universidad de Buenos Aires. Título original: The Origin and Scope of the American Doctrine of Constitutional Law, publicado originalmente en Harvard Law Review, tomo 7, número 3 (25 de octubre de 1893), págs. 129-156.

2 Conferencia pronunciada en Chicago, el 9 de agosto de 1893, en el Congreso de Filosofía del Derecho y Reforma Legislativa.

3 (1831-1902). Se graduó en la Facultad de Derecho de Harvard en 1856. Entre sus obras, se destacan las siguientes: Cases on Evidence (Casos sobre la prueba) (1892); Cases on Constitutional Law (Casos sobre el derecho constitucional) (1895); A Preliminary Treatise on Evidence at the Common Law (Tratado preliminar sobre la prueba en el Common Law) (1898) y una pequeña biografía de John Marshall (1901).
} 
estaduales, al tiempo que admitió que en la Constitución de los Estados Unidos dicha facultad estaba conferida por la segunda cláusula del artículo VI, en la que se dispone que la Constitución y las leyes y tratados concluidos en virtud de ella "serán la ley suprema del país; los jueces de los estados estarán obligados por ellos, independientemente de que existan disposiciones contrarias en la Constitución o en las leyes de un estado". ${ }^{4}$

Resulta insuficiente fundamentar esta notable facultad en el mero hecho de que una constitución sea escrita o en que los jueces hayan jurado defenderla. Ni la forma escrita ni el juramento de los jueces implica necesariamente el derecho de revocar o rechazar un acto emanado del Poder Legislativo o del Poder Ejecutivo que estos poderes están autorizados a emitir conforme a la Constitución, ni la afirmación por parte de estos poderes de que están autorizados para así obrar. Para confirmar esta aserción, basta con referirse al hecho de que otros países, como Francia, Alemania y Suiza, tienen constituciones escritas y esta facultad no se reconoce en ellas. En su admirable obra Law of the Constitution (El derecho de la Constitución), Dicey sostiene que "los límites a los actos del Congreso conforme a la Constitución de Francia no son, en realidad, leyes, dado que no son reglas que en última instancia puedan ser aplicadas por los tribunales. Su verdadero carácter es el de máximas de moralidad política, que derivan la fuerza que tengan de estar incluidas formalmente en la Constitución y del consiguiente apoyo de la opinión pública". 5

\footnotetext{
4 Aunque parezca extraño, este fallo ha caído en el olvido. Contiene el tratamiento más calificado que he visto, sin exceptuar la sentencia de Marshall en Marbury v. Madison, que, en mi opinión, ha sido sobreestimada. Gibson luego adhirió a la doctrina generalmente aceptada. En Norris v. Clymer, 2 Pa. St., pág. 281 (1845), el presidente de la Corte manifestó a los letrados: "Me aparté de ese fallo por dos razones: por un lado, porque la última convención [todo parece indicar que se refiere a la que dio lugar a la Constitución de Pensilvania de 1838] aprobó, con su silencio, la pretensión de los tribunales de examinar libremente los actos legislativos y, por el otro, sobre la base de mi experiencia en cuanto a las necesidades planteadas por cada caso en particular".

5 Capítulo II, pág. 127, 3. a ed. El presidente Rogers, en el prefacio a una valiosa colección de artículos sobre la "Constitutional History of the United States, as seen in the Development
} 
¿Cómo llegamos a adoptar esta destacable práctica? Principalmente, como resultado natural de nuestra experiencia política previa a la Guerra de la Independencia, como colonos gobernados por cédulas reales escritas provenientes de la Corona inglesa. Los términos y los límites de estas cédulas, como muchas constituciones escritas, se ejecutaban a través de diferentes medios: por la pérdida de las cédulas, por ley del Parlamento, por la anulación directa de la legislación por parte de la Corona, por un proceso judicial y un recurso en última instancia ante el Consejo Privado del Monarca. Nuestra práctica fue el resultado natural de esto, pero bajo ningún punto de vista fue un resultado necesario. Todo este sistema colonial de restricciones constituía solo el ejercicio normal y habitual del poder. Una autoridad externa había impuesto los términos de las cédulas, la autoridad de un gobierno principal, totalmente organizado y equipado para lidiar con cualquier problema de desobediencia, con un rey, un poder legislativo y tribunales propios. El derecho y la autoridad superiores de este gobierno eran fundamentales aquí, así como plenamente reconocidos; era solo un trámite usual, ordenado y necesario que nuestros tribunales hicieran valer los mismos derechos que reconocían los tribunales de apelación de Inglaterra. Estas cédulas eran, en sentido estricto, derecho escrito: tal como sus restricciones sobre las legislaturas coloniales eran ejecutadas por los tribunales ingleses de última instancia, también podían ejecutarse mediante los tribunales coloniales, considerándose nulo todo lo que las contradijera. ${ }^{6}$

\footnotetext{
of American Law" (Historia constitucional de los Estados Unidos, según el desarrollo del derecho estadounidense), pág. 11, destaca que "en la actualidad, no existe en Europa tribunal alguno con competencia para fallar sobre la constitucionalidad de las leyes nacionales. Pero, en Alemania y en Suiza, si bien los tribunales federales no pueden revocar una ley federal, sí pueden declarar la invalidez de una ley cantonal o estadual en caso de que entre en conflicto con el derecho federal". Compárese Dicey, ut supra, y Bryce, Am. Com., i. 430, nota (primera edición), respecto de posibles observaciones a esta afirmación.

6 Para conocer los casos más famosos Lechmere v. Winthrop (1727-28), Phillips v. Savage (1734) y Clark v. Tousey (1745), véase Talcott Papers, Conn. Hist. Soc. Coll., iv 94, nota. Agradezco a Mellen Chamberlain, de Boston, por la referencia de este volumen. La decisión
} 
Llegó la Revolución, ¿y qué pasó después? Fácil: cortamos el cordón que nos unía a Gran Bretaña y ya no hubo un soberano externo. Nuestra concepción fue que "el pueblo" había tomado ese lugar; es decir, nuestra propia población —ubicada en los diferentes estados - era el soberano. Si bien las instituciones existentes no se tocaron, sí se interpretaron mediante la traslación del nombre y del estilo del soberano inglés al nuevo gobernante: nosotros mismos, el pueblo. Después de esto, las cédulas, y con más razón las nuevas constituciones, no eran órdenes que venían desde afuera, respaldadas por un gobierno externo organizado que simplemente cumplía una función de rutina al ejecutarlas; eran preceptos emanados del pueblo mismo que iba a ser gobernado, dirigidos a cada uno de sus habitantes y especialmente a aquellos responsables de llevar adelante el gobierno. No existía un poder superior que respaldara estas órdenes mediante los métodos de coacción habituales. El soberano mismo, habiendo escrito estas expresiones de su voluntad, se esfumó; en la práctica, no tenía órgano alguno para ejecutar su voluntad, excepto aquellos a quienes se dirigían sus órdenes en estos documentos. Entonces, ¿cómo se ejecutaría su Constitución escrita si estos organismos no le obedecían, si fallaban o funcionaban mal?

En este punto surge un problema diferente del que se había presentado en el viejo orden y, sin embargo, nos encontramos con que no se dictaron nuevas disposiciones para abordarlo. Se siguieron los métodos y las concepciones de antaño. En 1776, en Connecticut, mediante una mera ley, la cédula de 1662 se declaró continuadora de la "Constitución civil del estado, bajo la única autoridad de su pueblo, independiente de todo rey o príncipe"; también se agregaron dos o tres reglas fundamentales y conocidas sobre la libertad y el buen gobierno. El pueblo de Connecticut vivió conforme a este régimen hasta 1818. En Rhode Island, la cédula, sin modificaciones, rigió hasta 1842, y,

del Consejo Privado del Monarca, contenida en Lechmere v. Winthrop, mediante la que se declara la nulidad de una ley provincial que rigió durante casi treinta años, se encuentra en Mass. Hist. Soc. Coll., sexta serie, v. 496. 
como se sabe, en relación con ella surgió uno de los primeros casos de acción judicial frente a un acto legislativo para solicitar la aplicación preeminente de disposiciones constitucionales conforme al nuevo orden, específicamente, el caso Trevett $v$. Weeden, en la Suprema Corte de Rhode Island en 1786. ${ }^{7}$

Pero resulta instructivo ver que esta nueva aplicación del poder judicial no tuvo aceptación universal. Fue rechazada por varios miembros de la convención federal y varios jueces se refirieron a su inestabilidad durante las últimas dos décadas del siglo pasado. La sorpresa de la Legislatura de Rhode Island frente a la acción del tribunal en Trevett $v$. Weeden parece indicar que pensaban que el cambio de la dependencia colonial hacia la independencia había transformado al Congreso en un sustituto del Parlamento, con una omnipotencia similar. ${ }^{8}$ Parece que en Vermont la doctrina establecida en el período era que el Poder Judicial no podía desestimar un acto legislativo, y la misma visión se sostuvo en Connecticut, tal como lo expresó Swift —quien luego se convertiría en presidente de la Suprema Corte de ese estado- en 1795. En el prefacio de ID. Chipman's (Vermont) Reports, 22 y siguientes, el sabio compilador, que escribía (en 1824) sobre el período de la Constitución de Vermont de 1777, manifestó: "No se sostenía que el Poder Judicial tuviera facultad alguna de analizar la constitucionalidad de los

\footnotetext{
7 Informe del caso de Varnum (Providence, 1787); s. c. 2 Chandler's Crim. Trials, 269.

8 Y lo mismo con el entusiasmo generado por la supuesta anulación de un acto legislativo en Nueva York en 1784, en el caso Rutgers v. Waddington. Edición de este caso por Dawson, "With an Historical Introduction" (Con una introducción histórica) (Morrisania, 1866), págs. xxiv y siguientes. En un "Address to the People of the State" (Discurso al pueblo del estado) emitido por el comité de una reunión pública de los "violentos Whigs", se declaró (pág. xxxiii): "el hecho de que deba existir una facultad correspondiente a los tribunales de justicia por medio de la cual se controle el poder legislativo supremo nos parece absurdo en sí mismo. Esas facultades en manos de los tribunales destruirían la libertad y eliminarían la seguridad de la propiedad". Por la referencia de este caso y de varios otros, estoy agradecido a un esclarecedor artículo sobre "The Relation of the Judiciary to the Constitution" (La relación del Poder Judicial con la Constitución) (19 Am. Law Rev. 175), del Dr. William M. Meigs, matriculado en el Colegio de Abogados de Filadelfia. Cita todos los primeros casos que se plantearon. Como remarca Meigs, el caso de Nueva York no parece referirse a la declaración de inconstitucionalidad de una ley.
} 
actos del Congreso, de declararlos nulos por algún motivo o incluso de cuestionar su validez". En la página 25, en referencia al año 1785, agregó: "Mucho después del período al cual hemos aludido, la doctrina de que la Constitución es la ley suprema de la nación y de que los tribunales pueden anular [...] leyes que sean contrarias a ella era considerada antirrepublicana". En $1814,{ }^{9}$ por primera vez, creo, encontramos un tribunal que declara que una ley de la Legislatura estadual es "nula por contradecir las Constituciones del estado y de los Estados Unidos, e incluso las leyes de la naturaleza". Cabe destacar que la doctrina por la que se declara la nulidad de ciertos actos legislativos por considerarlos contrarios a la Constitución probablemente haya surgido gracias a una teoría que encontró adeptos entre nuestros ancestros en la época de la Revolución, consistente en que los tribunales podían desestimar dichas leyes en caso de ser contrarias a las máximas fundamentales de la moral o, como se decía en ese entonces, de las leyes de la naturaleza. Se cree que dicha doctrina fue postulada por escritores ingleses e incluso por jueces, en algún momento, pero nunca se aplicó. Ha sido repetida aquí, como especulación, por nuestros primeros jueces y ocasionalmente por otros más recientes, pero no me consta que se la haya aplicado como único y necesario fundamento de una decisión — ni se la puede aplicar, a menos que tome la forma de una medida revolucionaria-. ${ }^{10}$

En "System of the Laws of Connecticut" (Sistema de las leyes de Connecticut), publicado en $1795,{ }^{11}$ el autor ataca con fuerza

9 Dupuy v. Wickwire, I D. Chipman, 237.

10 Este tema es objeto de un detenido análisis en la nota a Paxton's Case (1761), Quincy's Rep. 51, en relación con los Writs of Assistance, supuestamente confeccionados por el Dr. Horace Gray, actualmente juez de la Corte Suprema de los Estados Unidos. Véase la nota en las páginas 520-530. James 0tis manifestó en su alegato que "una ley del Parlamento contraria a la Constitución es nula" (Quincy, 56, n., 474). Se concluirá, luego de un examen pormenorizado, que los casos estadounidenses referidos a la nulidad de un acto legislativo, al ser contrarios a los principios de la moral o de gobierno - por ejemplo, en Quincy, 529, cita de Bowman v. Middleton, 1 Bay, 252 y en 1 Bryce, Am. Com., 431, n., 1. a ed., cita de Gardner v. Newburgh, Johns. Ch. Rep. 162-, no requerirán dicha explicación.

11 Vol. i. págs. 50 y siguientes. 
y argumentos la facultad del Poder Judicial de desconocer una norma legislativa, al tiempo que afirma que la opinión contraria "es muy popular y está muy extendida". Manifiesta: "Se estará de acuerdo en que es tan probable que el Poder Judicial declare la inconstitucionalidad de leyes que no son inconstitucionales como que el Congreso se exceda en sus atribuciones constitucionales". Pero admite que pueden darse casos tan monstruosos (por ejemplo, una ley que autorice a condenar por un delito sin pruebas o que asegure los escaños de los legisladores de por vida), "tan abiertamente inconstitucionales que parecería equivocado exigir que los jueces respetaran esa ley en sus fallos". En 1807 y 1808, la Legislatura de Ohio sometió a juicio político a jueces que habían fallado que leyes emanadas de ese órgano eran nulas. ${ }^{12}$

II. Cuando finalmente esta facultad del Poder Judicial quedó establecida y se agregó al resto de los baluartes de nuestras constituciones escritas, ¿cómo habría de concebirse este poder? Estrictamente como una facultad judicial. Las constituciones estaduales habían sido escrupulosas al dividir los poderes de gobierno en tres y, al dar a cada uno una facultad, les había prohibido a su vez, con curiosa explicitud, el ejercicio de facultades propias de otros poderes. En 1780, la Constitución de Massachusetts establecía que el Poder Legislativo: ${ }^{13}$

"No podrá ejercer jamás los poderes ejecutivo ni judicial; el Poder Ejecutivo no podrá ejercer los poderes legislativo ni judicial; el Poder Judicial no podrá ejercer los poderes legislativo ni ejecutivo; en suma, se tratará de un gobierno de leyes y no de hombres".

Con énfasis similar, en 1792, la Constitución de Kentucky ${ }^{14}$ estableció:

\footnotetext{
12 Cooley, Const. Lim., 6. ${ }^{\text {a }}$ ed., 193, n.; 1 Chase's Statutes of Ohio, prefacio, 38-40. Por la última referencia, debo agradecer al profesor Wambaugh.

13 Parte I, art. 30.

14 Art. I.
} 
"Cada uno estará confiado a un órgano separado; es decir, los que pertenezcan al Poder Legislativo, los que pertenezcan al Poder Ejecutivo y los que pertenezcan al Poder Judicial. Ninguna persona o grupo de personas, que pertenezcan a dichos poderes, ejercerán facultades propias de los otros, con las excepciones que se admiten expresamente a continuación".

Por lo tanto, como la facultad en cuestión era meramente judicial, en primer lugar, había muchos casos en los que no era operativa. En el caso de actos puramente políticos y del ejercicio de la mera discrecionalidad, no importaba que los demás poderes violaran la Constitución, ya que el Poder Judicial no podía interferir; todo lo contrario: debían aceptar y ejecutar sus actos. Hace poco el juez Cooley expresó: ${ }^{15}$

"La impresión común es, sin dudas, que, en caso de legislación en la que se desestimen los límites de la autoridad constitucional, [...] el Poder Judicial es totalmente competente para lograr una solución adecuada; que la ley deba de hecho ser nula y que cualquier ciudadano, así como el Poder Judicial mismo, pueda considerarla nula y negarse a obedecerla. Sin embargo, esto está lejos de ser así en los hechos".

Nuevamente, cuando la facultad del Poder Judicial sí tenía aplicación, este era su alcance total, es decir, determinar, a los meros efectos de fallar una cuestión presentada debidamente ante el tribunal, si un ejercicio de esa facultad objeto de controversia estaba prohibido por la Constitución. Al obrar así, el tribunal actuaría de manera tal de no privar a otro poder de sus facultades propias ni de limitarlas en función de su discrecionalidad. Estas cuestiones, una vez presentadas ante los tribunales para instar la acción de la justicia, no solo requieren un método particularmente amplio en su tratamiento, sino que específicamente requieren que los jueces acepten el rango vasto e indefinible de las facultades y decisiones legislativas, ese amplio margen de consideraciones referidas exclusivamente a criterios de orden práctico de un órgano legislativo. Dentro de

\footnotetext{
15 Journal of the Michigan Pol. Sc. Association, vol. i. pág. 47.
} 
ese margen, como en todas esas consideraciones legislativas, los legisladores constitucionales deben tener permitido cierto grado de libertad. En tanto las decisiones legislativas, libres de restricciones, pueden traducirse en una forma de acción u otra, los jueces no deben interferir, ya que la naturaleza de la cuestión planteada ante ellos es meramente judicial.

Asimismo, tal es la naturaleza de esta particular cuestión judicial que la determinación preliminar del Congreso es un hecho de gran importancia, ya que las constituciones expresamente confían al Poder Legislativo esta determinación; no pueden actuar sin llevarla a cabo. Además, las constituciones no solo encomiendan a las legislaturas una determinación preliminar de la cuestión, sino que contemplan que esta determinación puede ser la definitiva, ya que no garantizan revisión alguna de ella. Solo a medida que surjan litigios y que su trámite ponga sobre el tapete el tema de la constitucionalidad pueden emerger cuestiones para los tribunales de manera regular. Puede darse, entonces, el caso de que la decisión legislativa logre resultados en todo el país de una importancia fundamental antes de que surja o pueda decidirse una cuestión judicial, como en el caso de la primera y la segunda edición de la carta orgánica del Banco de los Estados Unidos y de las leyes sobre moneda de curso legal de hace treinta años y posteriores. La constitucionalidad de la carta orgánica de un banco dividió al gabinete de Washington tal como dividió a los partidos políticos durante más de una generación. Sin embargo, cuando se dictó la primera carta orgánica, en 1791, que estaría en vigor veinte años, no fue impugnada en sede judicial y fue renovada en 1816. Solo tres años después surgió la cuestión de su constitucionalidad ante la Corte Suprema de los Estados Unidos. Es particularmente importante observar que ese resultado no es excepcional o imprevisto; ha sido claramente previsto. Es al Congreso al que se otorga esta facultad, que no se limita solo a la aprobación de leyes, sino a la fijación de una interpretación de la Constitución que afectará profundamente a toda la nación, cambiará radicalmente e incluso revolucionará los asuntos más graves, excepto que un sujeto 
decida por su propio interés llevar el asunto a los tribunales. Lo mismo puede decirse de la legislación sobre moneda de curso legal de 1863 y la posterior. Sería difícil pensar en una norma más importante, más íntimamente ligada a los intereses de cada miembro de nuestra población. Si bien ahora se la confirmó, su constitucionalidad fue rechazada en un primer momento por la Corte Suprema de los Estados Unidos. Los tribunales locales estaban divididos y la opinión de los profesionales siempre ha estado dividida. Sin embargo, fue el Congreso el que determinó esta cuestión, no solo de forma primaria, sino de una vez y para siempre, salvo que algún sujeto considerara provechoso para su interés interponer una acción judicial.

Es claro que cuando se otorga una facultad tan trascendental como esta autoridad primaria para interpretar, las determinaciones efectivas del órgano al que se otorga esa facultad tienen derecho al correspondiente respeto; y esto no se basa en razones de cortesía o respeto convencional, sino en fundamentos muy sólidos y significativos de política y derecho. Los jueces bien pueden razonar que si han sido considerados por el pueblo como la protección principal ante las violaciones legislativas de la Constitución, no se les podría haber confiado este mero control incidental y posterior. Se les habría permitido, como se pretendió en algunas convenciones, una revisión de las leyes antes de que entraran en vigor. ${ }^{16}$ El hecho de que la oportunidad

16 La Constitución de Colombia, de 1886, en su art. 84 dispone que los jueces de la Corte Suprema pueden participar en los debates legislativos de "proyectos relacionados con asuntos civiles y el procedimiento judicial". Y, en el caso de los proyectos de ley objetados por "el Gobierno" por considerarlos inconstitucionales, si el Congreso insiste en el proyecto, en contra del veto del Gobierno, se presentará a la Corte Suprema, que decidirá en última instancia sobre esta cuestión. Artículos 90 y 150.

Siempre pensamos que el Poder Judicial tiene facultades de revisar los actos del resto de los poderes, lo que nos garantiza una protección ante la opresión y la ruina. Pero es de destacar lo poco que esto importó en los debates. Las principales protecciones eran un sufragio amplio, cargos cortos, un Poder Legislativo con dos cámaras y el llamado veto del Poder Ejecutivo. En general, existía un gran rechazo a otorgar al Poder Judicial facultad alguna en la aprobación de legislación. Sin embargo, en Nueva York, la Constitución de 1777 estableció un Consejo de Revisión — del que formaban parte varios jueces - a quienes se presentarían todos los actos legislativos antes de que entraran en vigor, previo a lo cual se requería de 
de los jueces de controlar y corregir leyes inconstitucionales sea tan limitada puede ayudarnos a entender por qué su control, cuando tienen la oportunidad de ejercerlo, debe ser de tan limitado alcance.

En ese entonces, era francamente indiscutible, además de previsible, que una gran parte de lo que es dañoso e inconstitucional puede entrar en vigor sin que los tribunales lo puedan evitar, dado que su poder es esencialmente judicial. Su intervención era solo una de las diferentes garantías y su alcance era acotado.

Muchas veces se reconoce, sin cortapisas, el rigor de esta limitación sobre la acción judicial, aunque de un modo perverso que en realidad opera para ampliar la función judicial más allá de sus justos límites. Suelen decirnos que el deber de

su aprobación. Este mecanismo existió durante más de cuarenta años, lo que dio lugar en la Constitución de 1821 al recurso ordinario de requerir la mera aprobación del Poder Ejecutivo o, en caso de que este la rechazara, de volver a aprobar la ley, tal vez mediante un voto con mayoría agravada, por ambas cámaras del Poder Legislativo. En Pensilvania (Constitución de 1776, art. 47) y en Vermont (Constitución de 1777, art. 44) se instituyó un Consejo de Censores que, elegidos cada siete años, investigarían la conducción de los asuntos y llamarían la atención, entre otras cosas, sobre todas las violaciones de la Constitución por alguno de los poderes del Estado. En Pensilvania, este arreglo duró solo entre 1776 y 1790; en Vermont, entre 1777 y 1870. Al elaborar la Constitución de los Estados Unidos, varios de esos recursos y otros fueron instados y, a veces, adoptados; por ejemplo, en el caso de Nueva York. En diferentes oportunidades se propuso que el gobierno pudiera rechazar toda la legislación de los estados; que los gobernadores de los estados fueran designados por los Estados Unidos y pudieran rechazar la legislación estadual; que se designara un Consejo Asesor para el presidente, compuesto en parte por jueces, y que el presidente y las dos cámaras del Congreso pudieran solicitar la opinión de la Corte Suprema. Finalmente, la convención rechazó estas propuestas, se pronunció respecto de los recursos comunes de las dos cámaras legislativas, que representarían un control mutuo entre ellas, y de la revisión ejecutiva y el veto, calificado por la facultad legislativa de reconsideración y aprobación con mayoría de dos tercios; sobre la base de estas consideraciones y de que la Constitución, las leyes constitucionales y los tratados serían la ley suprema del país y obligarían a los jueces de los diferentes estados. Esta disposición, como lo indican sus palabras, fue insertada pensando en asegurar la autoridad del gobierno general frente a los estados, es decir, como característica esencial de cualquier sistema federal y no en referencia directa al resto de los poderes de los Estados Unidos. Su primera postulación fue que “las leyes de los Estados Unidos y los tratados son la ley suprema de los respectivos estados y obligan a los jueces de los estados por sobre sus propias leyes". 
los tribunales consiste simplemente en interpretar dos escritos y compararlos, como en el caso de dos contratos o dos leyes que se interpretan y comparan cuando se alega un conflicto; también, que consiste en declarar el verdadero significado de cada uno de ellos y, en caso de que se opongan, de hacer valer la Constitución como una obligación de rango superior. Esta es una tarea judicial ordinaria y humilde, como suelen decir los mismos tribunales. Este enfoque lleva fácilmente a una errónea desestimación de las consideraciones legislativas: no solo conduce a que se les niegue operación directa como fundamento de una sentencia, sino, lisa y llanamente, a que no se las tome en cuenta. En vez de tomárselas en cuenta y permitírseles fungir de posibles fundamentos para la acción legislativa, hay un tratamiento pedante y académico de los textos de la Constitución y de las leyes. Y, de este modo, nos vemos privados de la combinación entre el rigor de un abogado y la amplitud de miras de un estadista que debería encontrarse al lidiar con este tipo de cuestiones en el derecho constitucional. De este método mezquino tenemos muchas muestras; se encuentra con mucha facilidad en los volúmenes de nuestros repertorios actuales.

Sin embargo, para evitar caer en estos métodos estrechos y lineales, para evitar que los tribunales se olviden de que, como dijo Marshall, "estamos hablando de una Constitución”, estos preceptos literales sobre la naturaleza de la tarea judicial han estado acompañados por una regla de administración que ha tendido, en manos idóneas, a dar a los asuntos un cariz muy diferente.

III. Observemos el curso que han seguido los tribunales al ejercer esta interesante facultad jurisdiccional.

Comenzaron basándose en el simple argumento de que el Poder Legislativo solo tenía una autoridad delegada y limitada conforme a las constituciones y que estos límites, para ser operativos, debían considerarse normas de derecho, lo que implicaría que debían ser interpretados y aplicados por los tribunales. Esto se propuso como algo normal. El razonamiento era simple y de corte restrictivo. Tal fue el método de Hamilton en 
el Federalista, en $1788,{ }^{17}$ al referirse a la Constitución federal, pero con fundamentos aplicables - desde su punto de vistaa todas las demás constituciones. En 1787, la Suprema Corte de Carolina del Norte estableció que ninguna ley emanada del Poder Legislativo podía alterar la Constitución ${ }^{18}$ y que los jueces estaban obligados por la Constitución al igual que por cualquier otra ley; asimismo, toda ley contraria a la Constitución debía considerarse derogada. Wilson, en sus Lecciones de Filadelfia en 1790-1791, ${ }^{19}$ expresó que la Constitución era la ley suprema y que los jueces debían interpretarla y aplicarla. La legislación subordinada debía ceder ante la Constitución, y el hecho de que un poder del Estado infringiera la Constitución no justificaba que otro poder fuera cómplice de ello. En 1793, en Virginia, los jueces manifestaron que los tribunales simplemente debían tener en consideración el derecho todo, incluida la Constitución: solo debían exponer el derecho y aplicar la parte de él que fuera fundamental. ${ }^{20}$ Patterson, uno de los jueces de la Corte Suprema de los Estados Unidos, en 1795, en el circuito de Pensilvania ${ }^{21}$ manifestó que la Constitución es la licencia del Poder Legislativo; si sus leyes no concuerdan con ella, carecen de toda autoridad. En 1796, en Carolina del Sur, ${ }^{22}$ el asunto fue tratado por el tribunal como una mera cuestión de adecuación con la ley principal. Y ese fue, en 1802, el razonamiento del Tribunal General de Maryland. ${ }^{23}$ Finalmente, en 1803 llegó Marbury v. Madison ${ }^{24}$ con la misma línea argumental. El pueblo, se afirmaba, estableció límites escritos al Poder Legislativo; esos

\footnotetext{
17 N. ${ }^{0}$ 78, publicado por primera vez el 28 de mayo de 1788. Véase la edición de Lodge, págs. xxxvi y xliv.

18 Den d. Bayard v. Singleton, I Martin, 42.

19 Vol. i. pág. 460.

20 Kemper v. Hawkins, Va. Cas. 20.

21 Vanhorne's Lessee v. Dorrance, 2 Dall. 304.

22 Lindsay v. Com'rs, 2 Bay, 38.

23 Whittington v. Polk, 1 H. \& J. 236.

24 I Cranch, 137.
} 
límites se aplican a todos los actos legislativos viciados que, por serlo, no son derecho. Esta teoría está esencialmente ligada a la existencia de una constitución escrita. Corresponde al Poder Judicial decir qué es el derecho y, en caso de conflicto entre dos leyes, cuál debe imperar. En suma, el Poder Judicial debe declarar nulas las leyes contrarias a la Constitución; caso contrario, este instrumento carece de sentido. Después se agregó que esta facultad está expresamente otorgada en la Constitución federal.

La rigurosidad de estas observaciones es innegable. Tal como estaba presentado el asunto, las conclusiones fueron necesarias. Sin embargo, parte de esta argumentación omitió las notables peculiaridades del caso; se desenvolvió como si la Constitución se tratara de una carta poder del derecho privado y como si el deber del tribunal fuera similar a cualquiera de sus operaciones más comunes.

Pero estos simples preceptos se vieron complementados por una importante regla de administración que corrigió la operación de esos preceptos y trajo a colación importantes consideraciones que no habían sido advertidas en el razonamiento mencionado. En 1811, ${ }^{25}$ Tilghman, presidente del Tribunal de Pensilvania, al reafirmar la facultad de los tribunales de declarar la inconstitucionalidad de las leyes, pero rechazando su ejercicio en un caso en particular, expresó esta regla de la siguiente manera:

"Por razones de peso, se ha aceptado como principio en materia de interpretación constitucional por parte de la Corte Suprema de los Estados Unidos, de este tribunal y de cualquier otro tribunal prestigioso del país, que una ley del Poder Legislativo no se declarará nula a menos que la violación del texto constitucional sea tan manifiesta que no quede margen para una duda razonable".

¿Cuándo surgió esta regla de administración? Muy temprano. Observamos que hay referencias de que se hallaba plenamente establecida en 1811. En la consideración judicial más antigua que

25 Com. v. Smith, 4 Bin. 117. 
se conoce sobre las facultades de los tribunales en la materia y de la que se conservan registros - una discusión incidental que se dio en Virginia en 1782- ${ }^{26} \mathrm{si}$ bien la facultad general del tribunal aparece declarada por otros jueces con énfasis histriónico, Pendleton, presidente del tribunal, al negarse a expedirse sobre el tema, adelantó las razones de esta regla, al expresar lo siguiente:

"¿En qué medida este tribunal, en cuyo seno podría decirse que están concentradas las facultades jurisdiccionales, tendrá poder para declarar la nulidad de una ley aprobada conforme a los procesos previstos por el Poder Legislativo, sin ejercer las facultades propias de ese poder, en contra de los claros términos de la Constitución? Esta es una pregunta profunda, importante y -agregaría - de enorme trascendencia, cuya respuesta implicaría consecuencias respecto de las cuales los caballeros [...] no han expresado sus ideas".

Agregó que no era la oportunidad de considerar el tema. En 1793, cuando el Tribunal General de Virginia declaró la inconstitucionalidad de una ley, el juez Tyler remarcó: ${ }^{27}$

"Pero la violación debe ser directa y clara; de lo contrario, existe el peligro de que el Poder Judicial impida la operatividad de leyes que podrían producir un gran beneficio público".

En la convención federal de 1787 , si bien se reconoció la facultad de declarar la inconstitucionalidad de las leyes, también se admitió la existencia de límites a dicha facultad. En un intento por que los jueces revisaran todos los actos legislativos antes de que entraran en vigor, Wilson destacó que las leyes podrían ser peligrosas y destructivas o "tan inconstitucionales que se justificaría que los jueces rechazaran su entrada en vigor". En 1796, el juez Chase, de la Corte Suprema de los Estados Unidos, afirmó, sin determinar si un tribunal puede declarar la nulidad de una ley del Congreso: "soy libre de declarar que nunca ejerceré dicha facultad a menos que se trate de un caso muy claro". Y en 1800,

26 Com. v. Call, 4 Call, 5.

27 Kemper v. Hawkins, Va. Cases, pág. 60. 
en el mismo tribunal, en relación con una ley de Georgia, el juez Patterson, que ya había declarado la invalidez de una ley de Pensilvania como juez de circuito en 1795, expresó que para justificar la declaración de nulidad de una ley por parte de un tribunal, debía existir "una violación clara e inequívoca de la Constitución, no una insinuación dudosa y discutible".

En 1808, en Georgia, se trató el tema con vigor, en un pasaje citado por otros tribunales con aprobación. Al sostener la constitucionalidad de una ley, el juez Charlton, que redactó el voto del tribunal, reafirmó esta facultad en tanto la consideró inseparable de la organización del Poder Judicial. Pero luego se preguntó por el modo en que debía ejercerse dicha facultad:

"Al decidir sobre la operatividad constitucional de una ley, no debe recurrirse a dudas sutiles, a una exposición crítica de palabras, ni a reglas abstractas de interpretación, que son métodos aceptables en una disputa entre particulares. La violación de un derecho constitucional debe ser tan evidente como la comprensión de una verdad axiomática, como que las partes son iguales al todo. Procuraré ilustrar este concepto del siguiente modo: la primera sección del artículo segundo de la Constitución establece que la función ejecutiva corresponde al gobernador. Entonces, si el Poder Legislativo cediera el poder ejecutivo a una comisión permanente de la Cámara de Representantes, todos percibirían instantáneamente la inconstitucionalidad de la ley. Sin dudas, el Poder Judicial estaría autorizado a declarar la inconstitucionalidad de esa ley. Pero cuando existen dudas respecto de si el Poder Legislativo violó la Constitución, debe evitarse un conflicto, ya que existe la posibilidad de que la Constitución habilite al Poder Legislativo".

En Carolina del Sur, en 1812, el juez Waties, que siempre se distinguió por sostener la facultad del Poder Judicial de hacer caso omiso de las leyes inconstitucionales, repitió y reafirmó con solidez su posición:

"Tengo tanta noción del peso de este deber que, en caso de que una violación constitucional fuera manifiesta, no solo declararía la nulidad de esa ley, sino que pensaría que presté 
un servicio más importante para mi país que al llevar adelante las tareas cotidianas de mi despacho durante muchos años. [...] Pero, si bien reconozco esta facultad e insisto en su gran valor para el país, soy también consciente de la alta deferencia que se le debe a la autoridad legislativa. Esta autoridad es suprema en todos los casos en que no sea limitada por la Constitución, y, como es deber de los legisladores y de los jueces consultar la Carta Magna y conformar sus actos a ella, también debe presumirse que sus actos se adecuan a las disposiciones constitucionales a menos que lo contrario sea evidente. Esta confianza es necesaria para asegurar la debida obediencia a su autoridad. Si esto fuera puesto en tela de juicio con frecuencia, tendería a disminuir la veneración por las leyes que resulta esencial a los efectos de la seguridad y la felicidad de todos. Por ende, no estoy dispuesto a analizar con precisión escrupulosa la validez de una ley. Sería poco prudente. La interferencia del Poder Judicial en los actos legislativos —en caso de ser habitual y sobre la base de motivos dudosos- podría ocasionar una gran envidia hacia este poder y un perjuicio general que llevarían a la toma de medidas que derivarían en la pulverización de la independencia de los jueces y, por ende, del mejor mecanismo que existe para preservar la Constitución. La validez de una ley no debería cuestionarse a menos que sea tan manifiestamente violatoria de la Constitución que, al ser declarada por los jueces, toda persona razonable de la comunidad pueda percibir dicha violación. Mediante un ejercicio cuidadoso de esta facultad de control judicial, no se generará envidia alguna, se promoverá la confianza pública y sus efectos saludables se apreciarán en su justa medida". 28

28 Esta conocida regla fue establecida por Cooley (Const. Lim., 6. ${ }^{\text {a }}$ ed., 216) y defendida en enérgicas declaraciones judiciales y en una larga lista de citas provenientes de todo el país. En Ogden v. Saunders, 12 Wheat. 213 (1827), el juez Washington, luego de remarcar que la pregunta era dudosa, expresó: "Si pudiera basar mi opinión en favor de la constitucionalidad de la ley [... ] solo en esta duda, sentida y reconocida, eso solo — desde mi punto de vistasería una defensa satisfactoria de ella. Presumir la validez de una ley hasta que se pruebe que viola la Constitución más allá de una duda razonable representa un respeto debido [...] al órgano legislativo que dicta las leyes. Tal ha sido siempre el criterio de este tribunal ante 


\section{Acumulé estas citas, llegando hasta sus orígenes, para que quede claro que la regla en cuestión es algo más que una mera}

este asunto y sé que expresa la opinión sincera de todos y cada uno de los miembros de este órgano". En los Sinking Fund Cases, 99 U. S. 700 (1878), el juez Waite, que redactó el voto del tribunal, expresó: "Esta declaración [de que una ley del Congreso es inconstitucional] no debería hacerse nunca, excepto en un caso claro. Las leyes se presumen válidas desde todo punto de vista hasta que se demuestre lo contrario más allá de una duda razonable. Un poder del Estado no puede invadir las competencias de otro sin correr serios riesgos: la seguridad de nuestras instituciones depende en gran medida del riguroso cumplimiento de esta saludable regla". En Wellington et al., Petitioners, 16 Pick. 87 (1834), el juez Shaw, que redactó el voto del tribunal, destacó que correspondía "repetir lo que tanto han sugerido los tribunales de justicia de que, cuando se les solicite la declaración de invalidez de una ley, nunca lo harán a menos que la nulidad o la invalidez de la ley se encuentre demostrada — a su juicio— más allá de una duda razonable". En Com. v. Five Cents Sav. Bk., 5 Allen, 428 (1862), el juez Bigelow, presidente del tribunal, que redactó el voto de dicho órgano, manifestó: "Corresponde citar la regla afianzada por este tribunal de que las leyes aprobadas conforme a todas las formalidades y solemnidades requeridas para que tengan efecto como tales gozan de la presunción de validez en su favor; por ende, los tribunales no pueden declarar [...] su invalidez a menos que esta se demuestre más allá de toda duda razonable". Y finaliza con el corolario de esta regla establecida. En Ex parte M'Collum, 1 Cow. pág. 564 (1823), el juez Cowen (que redactó el voto del tribunal) explicó: “Para que un tribunal considere obligatorio declarar la inconstitucionalidad de una ley del Congreso, debe presentarse un caso en el que no pueda haber una duda razonable". En The People v. The Supervisors of Orange, 17 N. Y. 235 (1858), el juez Harris (que redactó el voto del tribunal) expresó: “No se puede declarar la nulidad de una ley por un mero conflicto interpretativo entre el Poder Legislativo y el Poder Judicial. Antes de declararse la nulidad, mediante sentencia judicial, de un producto del poder legisferante, debe surgir claramente que la ley no encuentra apoyo en un objetivo razonable 0 en una presunción admisible". En Perry v. Keene, 56 N. H. 514, 534 (1876), el juez Ladd (con la adhesión del resto de los miembros del tribunal) escribió: “Ciertamente el tribunal no debe amilanarse ante el cumplimiento de un deber constitucional, pero, al mismo tiempo, no le corresponde al Poder Judicial sentar un precedente de invasión de las competencias de los otros poderes. Hoy es una regla elemental en los estados de la Unión decir que antes de que podamos declarar la inconstitucionalidad de una ley, debemos estar totalmente convencidos — más allá de una duda razonable - de que el objetivo por el que se autoriza el impuesto es privado y no público". En The Cincinnati, etc., Railroad Company, 1 Oh. St. 77 (1852), el juez Ranney (que redactó el voto del tribunal) dijo: "Si bien el derecho y el deber de interferencia en un caso concreto están claros, los principios por los que un tribunal debería guiarse en un análisis de ese tipo también son igual de claros, tanto desde el punto de vista del principio rector como del de la autoridad. [...] El Poder Judicial solo puede negar la operatividad de una ley cuando hay una diáfana suposición de autoridad y una clara incompatibilidad entre la Constitución y la ley. Nunca se puede permitir tal interferencia en un caso dudoso. Esto es una consecuencia de la naturaleza misma de la cuestión en análisis. En los casos decididos se puede ver una línea argumental uniforme a este respecto. [...] En los tribunales estaduales también se encuentra una misma cadena ininterrumpida 
cuestión lingüística, una mera expresión de cortesía y deferencia. Implica mucho más. Los tribunales percibieron con mayor o menor claridad que este ejercicio de la función judicial va, en verdad, mucho más allá de los asuntos cotidianos que los jueces suelen describir. Si su deber en realidad consistiera mera y simplemente en determinar el significado del texto constitucional y de la ley atacada, a fin de establecer — como una cuestión académica- si, en opinión del tribunal, están en conflicto, sin dudas se trataría de un asunto elevado e importante, que implicaría importantes consideraciones públicas, pero, aun así, sería una función mucho más simple de lo que en realidad es. Dicho esto, aún queda por responder la pregunta trascendental: si, a pesar de todo, el tribunal puede desestimar la ley. No lo puede hacer como un mero trámite habitual, simplemente porque se concluya que, según una interpretación justa y fiel, la ley es inconstitucional. Este es específicamente el significado de la regla de adjudicación que establecen los tribunales. Solo pueden desestimar la ley cuando advierten que los legisladores no cometieron un mero error sino uno muy claro que no puede ser puesto en duda de manera racional. Este es el estándar que aplican los tribunales respecto de los actos legislativos, es decir, el criterio que aplican: no solo su consideración respecto de la constitucionalidad, sino su conclusión de qué se le permite a otro poder del Estado que, conforme a la Constitución, tiene la facultad de dictar las leyes. Esta regla reconoce que, teniendo en cuenta las exigencias importantes, complejas y siempre

de sentencias en el mismo sentido". En Syndics of Brooks v. Weyman, 3 Martin (La.), 9, 12 (1813), el tribunal estableció: "Nos reservamos la facultad de declarar la nulidad de toda ley que sea abiertamente violatoria de la Constitución, lo que debe surgir de manera manifiesta, sin lugar a dudas" (citado con aprobación en Johnson v. Duncan, Ib. 539). En Cotton v. The County Commissioners, 6 Fla. 610 (1856), el juez Dupont (que redactó el voto del tribunal), manifestó: "Es una facultad de la mayor trascendencia e importancia; no puede ejercerse a la ligera, ni en aquellos casos en que no pueda determinarse de manera certera e indubitable que el Poder Legislativo se excedió en sus facultades. En caso de que el tribunal tuviera alguna duda razonable, la presunción es en favor de la ley [... ]. Se pueden citar muchísimos fallos de los tribunales estaduales en respaldo de esta posición. [...] En caso de que exista alguno que constituya una excepción a la doctrina general, podemos asegurar que no lo hemos encontrado". 
crecientes del Gobierno, muchas parecerán inconstitucionales para un hombre o grupo de hombres, pero tal vez no para otros; que la Constitución admite diferentes interpretaciones; que hay una variedad de opciones y opiniones; que en dichos casos, la Constitución no impone al Poder Legislativo opinión alguna, sino que deja abierto este abanico de opciones; y que cualquier opción racional es constitucional. Este es el principio que confirma y respalda la regla que desarrollé. Su significado y efectos quedan insinuados, de manera clara y concisa, por un comentario del juez Cooley, ${ }^{29}$ en relación con que un miembro del Poder Legislativo puede votar contra una medida que, en su opinión, sea inconstitucional y, luego, si esa persona se convierte en juez y la medida que fue aprobada a pesar de su oposición llega a él por la vía judicial, puede tener que aceptar como su deber el declararla constitucional, a pesar de no haber cambiado un ápice su opinión.

Puede que alguien piense que estoy siendo sobreabundante sobre este tema y hurgando mucho en la forma de una frase. No creo que sea así. Soy consciente del peligro que dicha conducta entrañaría. Pero independientemente de lo que se pueda decir de casos específicos de textos judiciales descuidados o indecisos, no me parece posible explicar de manera liviana las tempranas, constantes y enérgicas declaraciones sobre este asunto. Su forma es tan conocida por los tribunales y tiene un significado tan claramente definido, adoptado con un acuerdo tan amplio y remarcado con tanta energía que no podemos permitirnos pensar en ella como un mero lugar común transmitido de manera cortés y sin complicaciones. Se ha tenido que sostener ante las negaciones y las controversias. Por cierto, el juez Gibson la cuestionó en 1825, al rechazar el poder general de declarar inconstitucional una ley. ${ }^{30}$ Si existe tal facultad, insistió (en la página 352), los derechos de las partes "dependerían, no de la significatividad de la supuesta discrepancia con la Constitución,

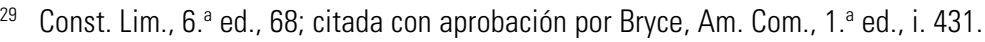

30 Eakin v. Raub, 12 S. \& R. 330.
} 
sino de la existencia misma de una discrepancia”. Pero la mayoría del tribunal reafirmó la facultad, y las limitaciones a ella, con el mismo énfasis. Esta regla también fue rechazada en 1817 por Jeremiah Mason, uno de los líderes del Colegio de Abogados de Nueva Inglaterra, en su alegato del caso del Dartmouth College, en su instancia anterior, en Nuevo Hampshire. ${ }^{31}$ Esto fue, en resumen, lo que dijo: "Aún prevalece una opinión errada por la cual los tribunales [...] deberían actuar [...] con precauciones mayores a las ordinarias, [...] que no deberían declarar inconstitucionales las leyes del Congreso a menos que lleguen a esa conclusión con una certeza absoluta [...] y con argumentos tan manifiestos y evidentes que nadie pueda dudar". Admitió que los tribunales deben tratar al Poder Legislativo "con mucho decoro, [...] pero [...] la decisión final, como en otros casos, debe basarse en los dictados de la imparcialidad según su entendimiento". Arguyó que las leyes requieren, para su aprobación, al menos una mayoría en el Congreso y que los argumentos contra la validez de la ley no pueden, por lo general, ser tan claros como para no dejar algún margen de duda. Por ende, la regla lleva a que el tribunal renuncie a su jurisdicción. "La experiencia muestra que los órganos legislativos tienen la costumbre de ejercer su poder con la mayor extensión posible”. Si los tribunales retroceden, cada vez que haya un posible margen de duda, el Congreso absorberá todo el poder. Esta era su posición, pero, no obstante, la Suprema Corte de Nuevo Hampshire estableció que ella no podía actuar sin "una convicción clara y sólida" y, en la instancia de apelación, en 1819, Marshall, en su celebrado voto de Washington, redactado en nombre del tribunal, expresó "que en ningún caso dudoso declararía que una ley es contraria a la Constitución".

Nuevamente, cuando el gran caso Charles River Bridge ${ }^{32}$ tramitó ante los tribunales de Massachusetts, en 1829, Daniel Webster, alegando - junto con Lemuel Shaw - en favor del actor,

\footnotetext{
31 Farrar's Rep. Dart. Coll. Case, 36.

327 Pick. 344.
} 
rechazó la existencia o la corrección de esta regla. En la página 442, afirmó que todos los casos de esa naturaleza implican algún tipo de duda; no puede imaginarse que el Congreso apruebe leyes que sean abiertamente inconstitucionales. El argumento adecuado es que el tribunal intervendrá cuando se advierta que un caso que parece dudoso es, en verdad, un caso de clara colisión con la Constitución. Agregó, además: "los miembros del Congreso muchas veces votan una ley sobre cuya constitucionalidad dudan, teniendo en cuenta que esa cuestión puede ser dirimida por los jueces”. Esta ley se aprobó en la Cámara de Representantes con una mayoría de cinco o seis.

"Podríamos demostrar, si correspondiera, que más de seis legisladores votaron en favor de la ley porque su inconstitucionalidad era dudosa, dejando la determinación final en manos de este tribunal. Si el Congreso aprueba una ley porque su inconstitucionalidad es dudosa y el juez confirma su validez porque su inconstitucionalidad es dudosa, me temo que los ciudadanos están en un aprieto. El Congreso la aprobó de manera condicional; si la cuestión no se decide aquí, no hay nadie que asuma la responsabilidad. [...] Corresponde a los jueces estadounidenses decidir las cuestiones constitucionales. [...] Los tribunales de justicia son los únicos adecuados para la investigación de complejas cuestiones de derechos de los particulares".

Pero el tribunal no cedió ante este ingenioso intento de convertirlo en un panel de resolución de acertijos legislativos. En vez de desviarse de la línea de su deber a los efectos de corregir los errores del Congreso, el tribunal sostuvo que el Poder Legislativo tiene sus propios deberes y su propia responsabilidad. En su voto, el juez Wilde expresó: "Dicha declaración solo debe hacerse cuando el caso es claro y evidente para toda mente inteligente. Debemos suponer que el Congreso cumplió con su deber y debemos respetar sus derechos y facultades constitucionales". Cinco años después, Lemuel Shaw, que se desempeñó como letrado asociado de Webster en el caso mencionado $-\mathrm{y}$ que ahora es presidente de la Suprema Corte de 
Massachusetts-, reiteró con mucho énfasis, en un caso ${ }^{33}$ en el que Jeremiah Mason era uno de los abogados, "lo que han sugerido en diferentes oportunidades los tribunales de justicia: que $[. .$.$] los tribunales [...] nunca declararán la nulidad de una$ ley a menos que la nulidad y la invalidez se demuestren más allá de una duda razonable".

Una regla atacada con argumentos tan fuertes y mantenida tan explícitamente debe tratarse como si hubiera sido pensada deliberadamente, tanto desde el punto de vista del fondo como de la forma. Respecto de su forma, llama más la atención porque marca un criterio conocido e importante, de aplicación cotidiana en nuestros tribunales, en situaciones en las que deben armonizarse los derechos, las acciones y la autoridad de los diferentes poderes, diferentes funcionarios y diferentes individuos. Puede agregarse que se trata de una distinción y una prueba que cobran cada vez más relevancia a medida que se complejiza y refina nuestra jurisprudencia. En una de sus aplicaciones, como todos sabemos, se utiliza constantemente en el derecho penal en materia de defensa propia, y en el derecho civil en el ámbito de la responsabilidad extracontractual en temas de culpa: al responder la pregunta de qué habría supuesto razonablemente como verdadero una persona que tiene el derecho y tal vez el deber de actuar en determinadas circunstancias. Es el criterio establecido para resolver la difícil cuestión de la responsabilidad de un soldado conforme al derecho patrio común cuando actuó conforme a las órdenes de su superior militar. Dicey, en su "Law of the Constitution" (Derecho de la Constitución), ${ }^{34}$ explica que "el soldado podría haber sido fusilado por una corte marcial en caso de que desobedeciera una orden y podría haber sido condenado a la horca por un juez y un jurado si la obedecía”. Continuó, citando con aprobación uno de los libros del juez Stephen, "Probablemente [...], se terminaría decidiendo que la orden de un superior militar

\footnotetext{
${ }_{33}$ Wellington, Perr., 16 Pick, 87.

34 3. ${ }^{\text {a }}$ ed., $279-281$.
} 
justificaría a sus subordinados al ejecutar órdenes respecto de las cuales podían suponer, con cierto grado de certeza, que su superior tenía buenas razones para impartirlas. [...] La única línea que se presenta en mi pensamiento es que un soldado debe ser protegido por órdenes respecto de las cuales pueda creer razonablemente que su superior tenía buenas razones". ${ }^{35}$ Esta es la distinción advertida por Lord Blackburn en un precedente moderno del derecho de la difamación". ${ }^{36}$ Dijo: "Cuando el tribunal decide si un determinado conjunto de palabras [...] es o no es difamatorio, los jueces tienen que tomar una decisión sobre una cuestión totalmente diferente de la que tienen que resolver al determinar si otro tribunal [...] no sostendría irrazonablemente que dichas palabras son difamatorias". Es la misma discriminación sobre la base de la cual todos los días se revisan los veredictos de los jurados en los tribunales, como en el famoso caso en el que Lord Esher la aplicó hace unos años, al negarse a revocar un veredicto. ${ }^{37}$ Afirmó que "debe parecer que personas razonables no podrían arribar a la conclusión del jurado. [...] De hecho, se ha dicho que la diferencia entre [esta] regla y la pregunta de si los jueces habrían decidido de la misma manera que el jurado es evanescente y que la solución en ambos casos depende de la opinión de los jueces. La última parte de la observación es verdadera, pero el modo en que se aborda el asunto marca la mayor diferencia. Preguntarse si habríamos llegado al mismo veredicto definitivamente no es lo mismo que preguntarse si hay posibilidad de una razonable diferencia de opinión". Del mismo modo, en relación con la actividad legislativa, suele plantearse una cuestión última -que fue resuelta en favor de los jueces en un reciente caso de gran

\footnotetext{
35 Así se sostuvo en Riggs v. State, 3 Cold. 85 (Term., 1866) y en United States v. Clark, 31 Fed. Rep. 710 (U. S. Circ. Ct., E. Dist. Michigan, 1887, juez Brown). Estoy en deuda por estos casos con la valiosa colección de Cases on Criminal Law (Casos de Derecho Penal) (Cambridge, 1893) del profesor Beale. La misma doctrina fue establecida por el juez Hare en 2 Hare, Am. Const. Law, 920.

36 Cap. \& Counties Bank v. Henty, 7 App. Cas, pág. 776.

37 Belt v. Lawes, Thayer's Cas. Ev. 177, n.
} 
trascendencia en la Corte Suprema de los Estados Unidos-: $:^{38}$ la de la razonabilidad del ejercicio por el Congreso de sus facultades más indudables, la del límite admisible de esas facultades. Si un Congreso se compromete a ejercer la potestad tributaria, la facultad de dominio eminente o alguna de las atribuciones propias de ese campo residual vasto y no clasificado de la facultad legisferante que se llama — no siempre atinadamentepoder de policía, esta acción no puede degenerar en un exceso irracional, para convertirse, en la realidad, en algo diferente y prohibido, como por ejemplo, la privación de la propiedad sin un debido proceso; y dicha determinación está en cabeza de los jueces. ${ }^{39}$ Sin embargo, debe recordarse que, en esos casos, la cuestión judicial siempre es secundaria. El Poder Legislativo, al decidir qué se debe hacer o qué es razonable hacer, no divide su deber con el de los jueces, ni debe adecuarlo a la concepción que tengan los tribunales de lo que es legislación prudente o razonable. La función judicial consiste meramente en fijar el límite externo de la acción legislativa razonable, la frontera que no pueden traspasar el poder tributario, el del dominio eminente y el poder legisferante en general sin violar las prohibiciones de la Constitución ni cruzar la línea de las disposiciones por las que esta otorga derechos. ${ }^{40}$ De hecho, debe

38 Chic. \& c. Ry. Co. v. Minnesota, 134 U. S. 418. La cuestión bajo análisis era la constitucionalidad de una ley que creaba una comisión regulatoria de las tarifas de trenes y que privaba a las partes del acceso a los tribunales para una revisión judicial final del actuar de la comisión.

39 Compárese con Law and Fact in Jury Trials, 4 Harv. Law Rev. 167, 168.

40 Suele haber una falta de discriminación en las expresiones judiciales sobre esta materia, como si se supusiera que el Congreso debería adecuarse a la opinión de razonabilidad del juez de una manera diferente de la indicada arriba. El juez Cooley, en sus Principles of Const. Law (Principios de Derecho Constitucional), 2. ${ }^{a}$ ed., 57, menciona la verdadera visión, cuando dice lo siguiente en referencia a una cuestión en particular: "En primer lugar, la determinación de qué es fin público corresponde al Congreso y su proceder no está sujeto a revisión o límites en tanto no sea claramente engañoso. Todos los casos de duda deben resolverse en favor de la validez de la acción legislativa, por la razón obvia de que el asunto es legislativo y solo se transforma en judicial cuando hay un manifiesto exceso de autoridad legisferante. Los tribunales solo pueden suspender el proceso y declarar la nulidad del embargo cuando la 
tenerse especialmente presente, al aplicarse en la esfera judicial este criterio acerca de qué podría pensar razonablemente un Congreso, que siempre han de atribuirse a dicho órgano virtud, buen sentido y conocimiento cabal. Los asuntos públicos siempre deben llevarse adelante sobre la base de convenciones y presunciones de ese tipo. El juez Gibson afirmó: "Es un postulado en la teoría de nuestro gobierno [...] que las personas son inteligentes, virtuosas y capaces para manejar sus propios asuntos". ${ }^{41} \mathrm{El}$ juez Marshall expresó: ${ }^{42}$ "sería extremadamente indecente, en un contrato entre dos particulares, inquirir respecto de la corrupción del poder soberano de un Estado". Por lo tanto, en la revisión judicial de los actos legislativos, así como de los actos de un jurado, el tribunal siempre presumirá que está frente a un órgano debidamente instruido; y la pregunta no es solo qué harían racionalmente las personas que vemos en nuestros órganos legislativos, personas que pueden ser ignorantes, rebeldes, desconsideradas, insensatas, incompetentes, sino qué pueden hacer las personas capaces, bien instruidas, sagaces, atentas, interesadas solo en el bien público, idóneas para representar a un pueblo soberano, tal como nuestra teoría de gobierno presume que son las encargadas de nuestros asuntos públicos; qué pueden pensar o hacer razonablemente esas personas, cuál es la visión de lo permitido para ellas. En caso de que, por ejemplo, se presentara ante el tribunal una cuestión sobre la constitucionalidad de una ley que se tacha de ser ex

ausencia de interés público en el propósito para el que se recaudan los fondos es tan clara y palpable que cualquier persona puede percibirla inmediatamente". En un asunto distinto, ante la Corte Suprema de los Estados Unidos, expresó el juez Waite, C., en Terry v. Anderson, 95 U. S. pág. 633: "En todos esos casos, la cuestión se refiere a la razonabilidad y, por ende, solo tenemos que considerar si este plazo de prescripción es razonable teniendo en cuenta las circunstancias. Sobre eso, el principal juez es el Congreso, y no podemos anular la decisión de ese poder del Estado a menos que se haya cometido un error manifiesto". Véase Pickering Phipps v. Ry. Co., 66 Law Times Rep. 721 (1892), y un valioso voto del juez Ladd, en Perry v. Keene, 56 N. H. 514 (1876).

41 Eakin v. Raub, 12 S. \& R., pág. 355.

42 Fletcher v. Peck, 6 Cr., pág. 131. 
post facto, no puede suponerse la ignorancia, aunque probable, respecto de ningún aspecto en un debate de alto nivel sobre ese asunto. Y lo mismo puede decirse de la prohibición de ser sometido a juicio dos veces por el mismo asunto o de declarar en contra de uno mismo, o de la pérdida de derechos civiles o del juicio por jurados. Entonces, la duda razonable de la que hablan nuestros jueces es la duda razonable que persiste en la mente de una persona capaz o debidamente instruida que se ha detenido a analizar la cuestión. La opinión razonablemente permisible de la que hemos hablado es la opinión razonablemente permisible a una persona de estas características.

El argumento en el que los tribunales se basan para establecer este criterio de la duda razonable para los jurados en el ámbito penal es la gravedad de afectar a un hombre con un delito. La razón por la que lo establecen para sí mismos al revisar el veredicto civil de un jurado es diferente, porque están revisando el trabajo de otro poder con un deber propio, sin tener ellos derecho alguno de asumir ese deber, excepto el derecho de contener al otro poder dentro de un límite de interpretación razonable y de ejercicio de sus facultades. El tribunal no debe, ni siquiera de manera negativa, expedirse sobre los hechos en los casos en que haya un jurado. La razón por la cual la misma regla se establece en relación con la revisión de los actos legislativos no es ni una ni la otra, sino ambas. Los tribunales revisan el trabajo de un poder coordinado y no deben, ni siquiera negativamente, legislar. Y, nuevamente, no deben actuar a menos que el caso sea muy claro, porque las consecuencias de declarar la nulidad de leyes pueden ser muy graves.

En caso de que se argumentara que la declaración de invalidez de leyes es diferente de los demás casos porque la cuestión última se relaciona con la interpretación de un escrito; que este tipo de cuestión siempre es una cuestión judicial y que no puede admitirse que haya dos interpretaciones legales del mismo instrumento; que se la puede interpretar correcta o incorrectamente, pero que hay solo un modo correcto; y que le 
corresponde al tribunal, en última instancia, decir cuál es ese modo correcto, esta sugerencia, a primera vista, parece tener mucha fuerza. Pero, en realidad, se plantea un interrogante. La opinión de Lord Blackburn en el caso de difamación ${ }^{43}$ se refería a la interpretación de un escrito. La doctrina que estamos considerando es la siguiente: al lidiar con la acción legislativa de un poder coordinado, un tribunal nunca puede decir que solo hay una manera correcta y permisible de interpretar la Constitución. Cuando un tribunal interpreta un escrito solo para determinar o aplicar su verdadero sentido, entonces solo hay un significado permisible; es decir, el que el tribunal considere el significado correcto. Pero cuando la cuestión no es esa, sino si ciertos actos de otro poder, funcionario o particular son legales o permisibles, esto no es así. En el tipo de casos que vimos, la cuestión en última instancia no es el verdadero significado de la Constitución, sino si la legislación puede sostenerse o no.

Puede sugerirse que este no es el modo en que los jueces tratan el asunto, por ejemplo que Marshall, en McCulloch $v$. Maryland, ${ }^{44}$ pretende establecer la opinión propia del tribunal sobre la constitucionalidad de la ley que crea el Banco de los Estados Unidos. Sin embargo, aun reconociendo que esto suele ser verdad, debemos recordar que, cuando un tribunal confirma una ley y la considera constitucional, es correcto que así lo declare, y dicha declaración es todo lo que se necesita en el caso; esa declaración resuelve el asunto. Pero no siempre es así. Hay muchos casos en los que los jueces confirman una ley porque están en duda sobre ella; casos en los que no dan su propia opinión respecto de su constitucionalidad, sino que simplemente dejan intacta una determinación del Congreso, como en el caso en que un juez de Massachusetts adhirió al voto de sus colegas respecto de que una ley era "apta para ser aprobada por el Congreso y no inconstitucional [...] sobre la base del único argumento de que la ley no es tan claramente

\footnotetext{
43 Cap. \& Count. Bank v. Henty, 7 App Cas. 741.

444 Wheat. 316.
} 
inconstitucional, ni su invalidez está tan libre de duda razonable, como para que sea un deber del Poder Judicial declararla nula en vista de los diferentes intereses involucrados en el resultado". ${ }^{45}$ La continua declaración de los jueces de que para ellos no se trata de una mera y simple preponderancia de razones a favor y en contra, sino de lo que es claro y evidente, claro más allá de toda duda razonable, es realmente un anuncio firme de que sus decisiones en favor de la constitucionalidad de la legislación no conllevan su propia opinión de la interpretación de la Constitución, y de que el significado estricto de sus palabras al declarar la constitucionalidad de una ley solo significa que no es inconstitucional más allá de una duda razonable. Puede agregarse que aquí reside la explicación para algunas de las decisiones que han alarmado a muchos en los últimos años, como si los tribunales fueran de poco fiar. ${ }^{46}$ Se pueden esperar muchas más opiniones de ese tipo, ya que, si bien los Congresos suelen faltar a su confianza, los jueces a veces deben admitir los límites de su propio poder.

Creo que todo se reduce a esto. La regla en discusión contiene un reconocimiento implícito de que el deber judicial en cuestión entra en el campo de la administración política y está delimitado por las necesidades y propiedades de la administración. Si nuestra doctrina de derecho constitucional — vaciada, como hemos visto, en el molde de un principio sustantivo expresado restrictivamente, con una regla de administración que expande una regla que, de lo contrario, sería muy restringida en su alcance- admite ahora una concepción más justa y más simple, estamos en presencia de algo muy habitual en el desarrollo del derecho. Esto fue lo que en verdad ocurrió al

\footnotetext{
45 Según el juez Thomas, The Opinion of Justices (La opinión de los jueces), 8 Gray, pág. 21.

46 "Poco importa, ya que el tribunal ha caído y no es probable que pueda volver a actuar como control eficaz de la voluntad popular 0 , en caso de que intentara hacerlo, que tenga éxito en ese intento", dijo un escritor deprimido, pero interesante e incisivo, al comentar, en 1885, las sentencias sobre la moneda de curso legal de la Corte Suprema de los Estados Unidos. "The Consolidation of the Colonies" (La consolidación de las colonias) de Brooks Adams, 55 Atlantic Monthly, 307.
} 
adoptarse nuestra teoría del derecho constitucional: presentamos, por primera vez, una aprobación judicial en el manejo del gobierno entre los grandes poderes del Estado; no completa, sino parcial. Los jueces quedaban autorizados, de manera indirecta y en cierta medida, a revisar el accionar de otros poderes y a declarar su nulidad. En rigor de verdad, si bien esta es una mera función judicial, implica, debido a la materia de la que se ocupa, participar, secundariamente, en la conducción política del Estado. Si esto es así, entonces los jueces deben aplicar métodos y principios a la altura de su tarea. En dicho trabajo, no puede existir arreglo permanente o adecuado entre los diferentes poderes a menos que cada uno esté seguro de la total cooperación del resto, en tanto su acción se adecue a una visión razonable y bastante permisible de su poder constitucional. El árbitro final de lo que es racional y permisible siempre es el Poder Judicial, siempre y cuando lleguen a él controversias que incluyan la cuestión. Esto pone en manos de nuestros tribunales una notable labor jurisdiccional. Solo se pondrá en peligro al conjunto si se busca darles más que eso. Los jueces no deben ponerse en el lugar del legislador ni hacer caso omiso del consejo que contiene el sagaz comentario de un obispo inglés de hace casi dos siglos, citado más tarde de las palabras del juez Holmes: ${ }^{47}$

"Quien tiene autoridad absoluta para interpretar las leyes escritas u orales es quien actúa como legislador, a todos los efectos, y no la persona que las escribió o pronunció por primera vez". ${ }^{48}$

\footnotetext{
47 Citado por el profesor Gray en 6 Harv. Law Rev. 33, n., donde señala con acierto que el comentario evidencia "que los caballeros de toga corta muchas veces comprenden los principios jurídicos mejor que muchos abogados".

48 Sermón del obispo Hoadly pronunciado ante el rey el 31 de marzo de 1717, sobre "The Nature of the Kingdom or Church of Christ" (La naturaleza del reino o la Iglesia de Cristo). Londres: James Knapton, T717. Debe tenerse en cuenta que el obispo Hoadly habla de una situación en la que el supuesto legislador, luego de dictar la ley, nunca se entromete. Ese no es exactamente el caso que tenemos entre manos; sin embargo, podemos recordar lo señalado por Dicey sobre la modificación de la Constitución de los Estados Unidos: “El soberano de los Estados Unidos se ha puesto en acción, pero solo una vez en noventa años. Necesitó
} 
V. Finalmente, permítaseme hacer brevemente una o dos consideraciones que suelen obviarse y que son importantes para lograr un entendimiento claro de la materia. Los jueces a veces tienen oportunidad de expresar su opinión respecto de la constitucionalidad de una ley cuando la regla que hemos considerado no se aplica o se aplica de un modo diferente del ordinario. Hay al menos tres situaciones que deberían distinguirse: 1) cuando los jueces se pronuncian sobre la validez de los actos de un poder coordinado; 2 ) cuando actúan como asesores de otros poderes; 3) cuando, en representación de un gobierno de autoridad preeminente, se ocupan de actos de un poder que no es coordinado.

1) El caso del tribunal que se expide sobre la validez de una ley de un poder coordinado es la situación normal, a la que se aplican las observaciones anteriores. No necesito decir nada más al respecto.

2) En relación con el segundo caso, la emisión de opiniones consultivas no constituye ejercicio de la función judicial, y las opiniones dadas en ese sentido no tienen nivel de autoridad judicial. ${ }^{49}$ Un fallo excepcional y $\sin$ apoyo, del estado de Maine, dictado en una época de gran entusiasmo político, ${ }^{50}$ y

del trueno de la Guerra Civil para interrumpir su reposo y es dudoso que algo que no sea una revolución inminente lo vuelva a llamar a la actividad. Pero un monarca que duerme durante años es como un monarca que no existe. Una constitución federal es susceptible de ser reformada, pero, a pesar de ello, una constitución federal tiende a la inmutabilidad".

${ }^{49}$ Com. v. Green, 12 Allen, pág. 163; Taylor v. Place, 4 R. I., pág. 362. Véase el Thayer's Memorandum on Advisory Opinions (Memorando de Thayer sobre las opiniones consultivas)

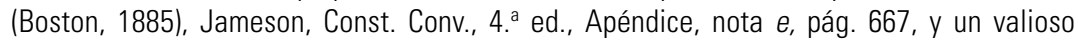
artículo de H. A. Dubuque, en 24 Am. Law Rev. 369. sobre "The Duty of Judges as Constitutional Advisers" (El deber de los jueces como asesores constitucionales).

${ }^{50}$ Opinion of Justices,(La opinión de los jueces) 70 Me., p. 583 (1880). Contra, juez Kent, en $58 \mathrm{Me}$, pág. 573 (1870): "Sin dudas, es verdad que las decisiones emitidas en virtud de un pedido de este tipo no tienen fuerza judicial alguna y que no pueden vincular ni controlar la acción de un funcionario de cualquier poder. Nunca se han considerado vinculantes para el órgano que las solicita". Y, en el mismo sentido, el juez Tapley, ibid., pág. 615: "Sin considerar jamás que esas decisiones eran concluyentes, sino abiertas a revisión en la ocasión adecuada"; y el juez Libby, en 72 Me., págs. 562-3 (1881): "En tanto cualquier decisión que se 
una doctrina del estado de Colorado, basada en consideraciones específicas de la Constitución de ese estado, ${ }^{51}$ no inspiran ninguna observación a la afirmación general de que esas opiniones, dictadas por nuestros jueces - como las conocidas opiniones emitidas en Inglaterra para asesorar a la Cámara de los Lores, que fueron el antecedente de nuestra práctica- son meramente consultivas y bajo ningún punto de vista constituyen sentencias autorizadas. ${ }^{52}$ Nuestras constituciones no permiten esas opiniones. En los seis o siete estados donde las constituciones las prevén, suelen informarse como parte de las decisiones ordinarias, así como se suelen citar las respuestas de los jueces en el caso de Queen Caroline y en el caso MacNaghten, como si tuvieran la misma jerarquía de fallos con contenido dispositivo. En relación con dichas opiniones, los escrúpulos, las precauciones y las advertencias a las que me he referido, y la regla de la duda razonable, que hemos visto remarcada por los tribunales respecto de las decisiones judiciales sobre la constitucionalidad de las leyes, no tienen aplicación. Lo que se solicita es la opinión personal del juez.

3) En el tercer supuesto entran las preguntas sobre la existencia de nuestro sistema doble, con dos constituciones escritas, y dos gobiernos, uno de los cuales tiene, dentro de su ámbito, mayor autoridad que el otro. La relación con los estados del gobierno principal en general, y su deber en todas las cuestiones relacionadas con las atribuciones del gobierno general para mantener dicho poder frente a los estados en su totalidad, también parecen dejar establecido el deber de cada uno de los poderes, que consiste en mantener esta autoridad superior en su justa y debida proporción, que cada poder determinará por sí mismo.

\footnotetext{
emita ahora no surtirá efecto alguno si el asunto se lleva a los tribunales mediante el proceso adecuado, y ante el temor de incumplir un deber constitucional si me niego a responder, expondré muy sumariamente mi opinión sobre la cuestión presentada". El juez Walton adhirió; los otros jueces no dijeron nada sobre este punto.

51 In re Senate Bill, 12 Colo. 466, decisión que me parece, en algunos aspectos, poco meditada.

52 Macqueen's Pract. Ho. of Lords, págs. 49-50.
} 
Si una legislatura estadual aprueba una ley que es impugnada durante el trámite del litigio ante los tribunales nacionales por estar en conflicto con la ley suprema de la nación, esos tribunales pueden tener que hacerse una pregunta diferente de la que correspondería si las leyes provinieran de un poder coordinado. Cuando la pregunta se refiere a qué se admite como no perteneciente al poder nacional, cualquiera que interprete una constitución estadual, ya sea el Poder Judicial nacional o estadual, debe permitir a esa legislatura el más amplio margen de interpretación racional. Sin embargo, cuando la pregunta es si un acto estadual se adecua a la Constitución principal, la ley máxima del país, estamos frente a un caso diferente. Fundamentalmente, se trata, en un caso como este, de la adjudicación de poder entre dos gobiernos; dónde se trazará esa línea. Es verdad que el Poder Judicial aún está debatiendo si una legislatura ha traspasado su límite, pero los poderes no son coordinados y el límite está en un punto diferente. El Poder Judicial ahora habla en representación de una Constitución y de un Gobierno principales, cuyo deber consiste, a través de todos sus poderes, en permitir a esa Constitución nada menos que su justa y correcta interpretación, y, hecho esto, en protegerla de avances externos.

Me he referido al Poder Judicial nacional. Respecto de cómo debe tratar el Poder Judicial estadual una controversia de inadecuación entre su propia Legislatura y la Constitución principal, se ha dicho, con razón, que debería regirse por la misma regla que aplicarían los tribunales federales. Dado que las apelaciones recaen en los tribunales federales, se ha dicho que estos dos tribunales deberían proceder sobre la base de la misma regla, al ser parte de un mismo sistema. Pero, conforme a la Ley de Organización del Poder Judicial, no todas las decisiones pueden apelarse, sino solo aquellas en las que subyace el derecho estadual. Tal vez sería sensato, a esta altura, aun si se permitiera la apelación en todos los casos, adherir a la regla general de que los jueces deben seguir la opinión que hubiera adoptado la Legislatura coordinada. En todo caso, conforme a la legislación existente, parece adecuado que los tribunales 
estaduales obren de este modo, por la razón práctica de que es necesario para preservar el derecho de apelación. ${ }^{53}$

La visión que se ha presentado me parece de suma importancia. No pretendo formular una nueva doctrina, sino que intento replantear con más exactitud y rigor una que ya está admitida. Si lo que he expuesto tiene solidez, sería muy bienvenido que los tribunales lo aplicaran en su máxima extensión. Se ha sostenido que los derechos privados suelen ser más respetados por los Congresos de los países que no tienen Constitución escrita que por el nuestro. No hay dudas de que nuestra doctrina del derecho constitucional ha tenido tendencia a dejar afuera cuestiones de justicia y derechos, y a llenar la cabeza de los legisladores con pensamientos sobre la mera legalidad, es decir, lo que permite la Constitución. De hecho, en relación con la legalidad, han sentido poca responsabilidad: "si estamos equivocados, los tribunales lo corregirán", dicen. ${ }^{54}$ Si lo que he dicho hasta aquí es verdad, el camino seguro y continuo hacia la reforma es el de recalcarle a nuestro pueblo un sentido más fuerte del que tienen respecto del amplio margen de posible dañosidad y maldad que nuestro sistema permite y debe permitir a los Congresos, y de los claros límites del Poder Judicial, a fin de que se dé a la responsabilidad el lugar que le corresponde.

53 Juez Gibson, en Eakinz' Raub, 12 S. \& R., pág. 357. Compárese lb., pág. 352. En líneas generales, el tribunal Ilega al mismo resultado, en Tonnage Tax Cases, 62 Pa. St. 286: "Un caso de simple duda debe resolverse en favor del derecho estadual, dejando la corrección del eventual error al Poder Judicial federal. La presunción en favor de un poder coordinado del Estado, la relación de sus tribunales con el Estado y, sobre todo, la necesidad de preservar el sistema económico clave para su bienestar, exigen esto de nuestra parte" (del juez Agnew, redactor del voto del tribunal).

54 "Una consecuencia singular de la importancia de la interpretación constitucional en los Estados Unidos [...] es que el Poder Legislativo de los Estados Unidos ha estado muy ocupado en debates puramente jurídicos. [...] Los asuntos jurídicos pueden eclipsar y oscurecer el tema (mucho más medular) de los principios y las políticas, distrayendo la atención del país así como las habilidades de los congresistas de ese aspecto tanto más importante", I Bryce, Am. Com., 1. a ed., 377. En la página 378 cita a uno de los escritores más conocidos de derecho constitucional, el juez Hare: "En el tratamiento refinado y sutil que sigue, muchas veces se confunde lo que corresponde o se trata como sinónimo de lo que podría ser. Se da por sentado que lo que permite la Constitución también está aprobado, y que las medidas que son legales no pueden ser contrarias a la moral". Véase también Ib., 410. 
El control y el recorte de la facultad legisferante, a través de numerosas y detalladas prohibiciones constitucionales, no puede lograrse sin reducir al Estado a una entidad insignificante y deficiente. Este proceso ya ha llegado demasiado lejos en algunos de nuestros estados. En ningún sistema el poder de los tribunales puede llegar tan lejos como para salvar a un pueblo de la ruina; nuestra principal protección reside en otra parte. Si esto es así, es de la mayor importancia pública exponer el asunto en su verdadera dimensión. 55

55 La volonté populaire : tel est, dans les pays libres de l'ancien et du Nouveau Monde, la source et la fin de tout pouvoir. Tant qu'elle est saine, les nations prosperent malgre les imperfections et les lacunes de leurs institutions : si le bon sens fait defaut, si les passions l'emportent, les constitutions les plus parfaites, les lois les plus sages, sont impuissantes. La maxime d'un ancien : quid leges sine moribus? est, en somme, le dernier mot de la science politique. — Le Systeme Judiciaire de la Grande Bretagne, de le Comte de Franqueville, i. 25 (Paris: J. Rothschild, 1893). 